\title{
Effects of Pulsed Unipolar and Bipolar Current Regimes on the Characteristics of Micro-Arc Oxidation Coating on LZ91 Magnesium-Lithium Alloy
}

\author{
Shuo-Jen Lee ${ }^{1}$,Le-Hung-Toan Do ${ }^{1, *}$, Jeou_long Lee ${ }^{2}$,Chang-Yong Chen ${ }^{3}$,Huan-Chih Peng ${ }^{1}$ \\ ${ }^{1}$ Department of Mechanical Engineering, Yuan Ze University, Chung-Li, Taiwan 32003, R.O.C. \\ ${ }^{2}$ Department of Chemical and Materials Engineering, Lunghwa University of Science and \\ Technology, Guishan, Taoyuan County 33306, Taiwan, R.O.C. \\ ${ }^{3}$ AMLI Materials Technology Co., Ltd., No.61-1, Chang'an St., Bade Dist., Taoyuan City 33465, \\ Taiwan, R.O.C. \\ *E-mail: toandlh@gmail.com, s1028705@mail.yzu.edu.tw
}

doi: $10.20964 / 2018.03 .42$

Received: 17 November 2017 / Accepted: 8 January 2018 / Published: 5 February 2018

\begin{abstract}
Micro-arc oxidation (MAO) coatings on magnesium-lithium alloys were performed in an alkalinesilicate electrolyte using pulsed unipolar and bipolar current regimes to improve the corrosion resistance. The effects of a negative duty cycle of a pulsed bipolar current on the coating performance were studied at 10\%, 20\% and 30\%. The surface morphology, element composition and phase composition of MAO coatings were examined by SEM, EDS and XRD, respectively. The corrosion resistance and porosity of the coatings were studied by potentiodynamic polarization which was performed in $3.5 \% \mathrm{NaCl}$ solution at $25^{\circ} \mathrm{C}$. The effects of the negative duty cycle on the MAO coating process and the resulting coating characteristics were discussed. Applying the pulsed bipolar current was found to promote a thinner compact coating. The corrosion resistance of the magnesium-lithium alloy was significantly improved after treatment with pulsed unipolar and bipolar current regimes. The results show that applying a $20 \%$ negative duty cycle in a pulsed bipolar current regime produces better corrosion resistance than $10 \%$ and $30 \%$ MAO coated samples.
\end{abstract}

Keywords: Micro-Arc Oxidation; unipolar current mode; bipolar current mode; negative duty cycle; Mg-Li alloy

\section{FULL TEXT}

(C) 2018 The Authors. Published by ESG (www.electrochemsci.org). This article is an open access article distributed under the terms and conditions of the Creative Commons Attribution license (http://creativecommons.org/licenses/by/4.0/). 